\title{
A Formação das Imagens no Turismo: itinerário teórico e proposta de um modelo operacional
}

The Tourist Image Formation: theoretical itinerary and a proposed operational model

\section{La Formación de la Imagen en el Turismo: itinerario teórico y propuesta de un modelo operativo}

Roque Pinto $^{1}$

\section{Resumo}

Para muitos autores a escolha do destino é o momento mais importante para o funcionamento de todo o sistema turístico, sendo a imagem do lugar de fruição turística sua componente mais significativa. Assim, pretende-se aqui desenvolver uma discussão sobre a formação da imagem turística, enfatizando algumas das principais contribuições derivadas das investigações especializadas sobre o tema. Partindo-se da proeminência do olhar do turista como fator decisivo para a afirmação do turismo no plano global, discute-se a relação entre a imagem do destino e a conduta do turista (enfoque estático), bem como a formação e as transformações da imagem turística em si mesma no tempo (enfoque dinâmico). Contudo, argumenta-se que a tendência dos estudos sobre a formação da imagem turística (TDI) parte do pressuposto falso de que o turista seria um reflexo do Homo economicus, marcado pelo racionalismo, utilitarismo e individualismo. Nesse sentido propõe-se um modelo alternativo pluralista e holístico - que procura relacionar as várias etapas do processo de formação da imagem dentro de uma perspectiva multidimensional, sistêmica e processual, situando simultaneamente os vários agentes envolvidos no sistema turístico.

Palavras-chave: turismo; formação da imagem turística; TDI.

\begin{abstract}
According to many authors the choice of destination is the most important moment for the functioning of the whole tourism system, and this most significant component it is the tourist image. So here aims to develop a discussion on the formation of the tourist image, highlighting some of the main contributions arising from scholarly research on the subject. Based on the prominence of the tourist gaze as a decisive factor for the affirmation of tourism at the global frame, we discuss the relationship between the destination image and the tourist behavior (static approach) as well as the formation and transformation of the tourist image

\footnotetext{
${ }^{1}$ Doutor em Antropologia Social pela Universidad de La Laguna (Tenerife, Espanha); Professor Adjunto de Antropologia na Universidade Estadual de Santa Cruz (Ilhéus, Brasil). Editor Temático do Periódico Pasos: Revista de Turismo y Património Cultural. E-mail: roquepintosantos@gmail.com.
} 
itself in time (dynamic approach). However, it is argued that the trend of studies on the "tourist destination image" (TDI) part of the false assumption that the tourist would be a reflection of Homo economicus, marked by rationalism, utilitarianism and individualism. In this sense it is proposed an alternative model - pluralistic and holistic - which seeks to relate the various stages of image formation in a multidimensional, systemic and processual approach, simultaneously placing the different social agents involved in the tourism system.

Keywords: tourism; tourist image formation; TDI.

\section{Resumen}

Según muchos autores la elección del destino es el momento más importante para el funcionamiento del sistema turístico como un todo, y su componente más importante es la imagen turística. Así que intentase en ese trabajo desarrollar un debate sobre la formación de la imagen turística, destacando algunas de las principales aportaciones derivadas de la investigación académica sobre el tema. Con base en la importancia de la mirada del turista como un factor decisivo para la afirmación del turismo en el marco global, podemos discutir la relación entre la imagen de destino y el comportamiento de los turistas (enfoque estático), así como la formación y transformación de la imagen turística propiamente dicha en el tiempo (enfoque dinámico). Sin embargo, argumentase que la tendencia de los estudios sobre la "imagen de destino turístico" (TDI) parte de la falsa suposición de que el turismo sería un reflejo del Homo economicus, marcado por el racionalismo, el utilitarismo y el individualismo. En este sentido, se propone un modelo alternativo -pluralista y holístico-que trata de relacionar las distintas etapas de formación de la imagen turística desde un enfoque multidimensional, sistémico y procesual, situando simultáneamente los distintos agentes sociales involucrados en el sistema turístico.

Palabras clave: turismo; formación de la imagen turística; TDI.

\section{Introdução}

É emblemática - e quase um senso comum na literatura especializada - a afirmação de que o turismo seria uma "indisciplina" (Tribe, 1997) ou mesmo uma "pós-disciplina" (Coles, Duval e Hall, 2005), considerado-se sua natureza altamente complexa, mutável e adaptável (Burns, 2002; Castaño, 2005; Barretto, 2007 e 2010; Santana Talavera \& Pinto, 2008; Pereiro, 2009; Santana Talavera, 2009; Pinto e Pereiro, 2010).

Dentro desta ambiência teórico-conceitual, marcada pela interdisciplinaridade e pela inconstância canônica, vêm se destacando desde a década de 1970 estudos sistemáticos sobre um campo teórico cujo objeto seria ainda mais instável: a formação da imagem turística, ou 
"Tourism Destination Image" (TDI). E que, no entanto, paradoxalmente, a despeito do seu caráter fugidio, representa um ponto de capital importância para o entendimento (na arena teórica) e o funcionamento (na arena empírica) de todo o sistema turístico.

Glosando criticamente e sopesando os avanços teórico-conceituais de alguns dos principais autores que investigaram mais sistematicamente este tema, propõe-se aqui uma nova abordagem, que se abre para o entendimento da formação das imagens dos destinos a partir das perspectivas dos vários atores que as compõem - e não apenas centradas na perspectiva do turista -, configurando-se como uma ferramenta teórica e metodológica útil para o melhor entendimento do processo geral de formação da imagem turística.

\section{O Olhar do Turista}

Uma das perspectivas de aproximação ao turismo que mais ganharam notoriedade na arena acadêmica nas últimas décadas deriva do trabalho seminal de MacCannel (1976), e é definida por alguns autores como o modelo semiológico, tendo como objeto central a proeminência do olhar do turista na concepção, conformação e desenvolvimento do espaço turístico (Crick, 1992; Simonicca, 2001 e 2007) $)^{2}$.

Essa abordagem presume que a própria atividade turística seria fruto de uma transformação profunda coincidente com a modernidade, que por sua vez teria na perspectiva visual seu dispositivo social e cognoscivo privilegiado, através do qual o sujeito moderno passaria a se relacionar com o mundo segundo uma ênfase numa sensibilidade ocular (Lash \& Urry, 1994; Appadurai, 1991 e 1995; Featherstone, 1989 e 1995; Urry, 1999).

Assim, esquematicamente, o paradigma semiológico de abordagem do turismo pode ser matizado a partir de duas tradições: uma anglo-saxã e outra francesa, ambas partindo do pressuposto duma espécie de cesura sensorial entre a modernidade e o passado.

\footnotetext{
${ }^{2}$ Em geral, no contexto estadunidense utiliza-se o termo semiótica, derivado da tradição peirceana, num sentido aproximativo ao termo semiologia desenvolvido por Saussaure, mais largamente utilizado em Europa. Embora com vários matizes teóricos e conceituais, ambos os termos se referem basicamente aos sentidos que são atribuídos ao mundo sensível através da mediação de signos (Cf. Burns, 2002).
} 
Na tradição anglo-saxã anota-se a ênfase na perspectiva do sightseer-turista sobre o espaço, isto é, parte-se do individual para o social, no sentido de uma análise sociológica sobre a formação das imagens desde o ponto de vista do turista (Chambers, 2000; MacCannel, 2003).

A variante francesa, numa orientação oposta, ressalta a configuração do imaginário da viagem e do turismo através da massificação midiática da vida social, portanto enfatizando a ambiência social como o parâmetro de formação da imagem turística (Augé, 1998 e 2001; Lagunas, 2007). No fulcro do modelo semiológico se encontra o debate sobre a autenticidade que, de acordo com Reisinger \& Steiner (2005), poderia ser matizado dentro de três perspectivas.

A primeira delas o situa como uma problemática modernista, inaugurada pela querela entre Boorstin (1961) e MacCannel (1976 e 2003), e marcada pela ideia de autenticidade significando o tradicional e o genuíno enquanto valores universais, numa visão romantizada e estática das sociedades não-industriais. Ao passo que para Boorstin toda experiência turística seria superficial e inautêntica, marcada por pseudo-eventos, na medida em que seria um reflexo do próprio mundo fictício do consumo da sociedade de massas, para MacCannel, o turista tipo-ideal, situado nas classes médias do ocidente industrializado, buscaria na alteridade da natureza, do passado ou do outro "étnico" um mundo autêntico inexistente na sua vida cotidiana. E o encontraria de forma comercializada e encenada no destino turístico, isto é no cenário (frontstage) montado para a satisfação do turista (Greenwood, 1977; Graburn \& Barthiel-Bouchier, 2001; Cohen, 2005; López Lara, 2005).

A segunda perspectiva pode ser classificada como construtivista, e pressupõe que o autêntico é fruto de uma realidade configurada a partir do olhar do observador e projetada através de estereótipos ocidentais sobre o outro. Assim, o autêntico se situaria não nos espaços em si, mas nas suas significações, sendo o apelo midiático e publicitário um importante agente nesse processo.

A terceira perspectiva se inscreve na agenda pós-moderna, para a qual a autenticidade não teria relevância para a fruição turística, sendo esta muito mais marcada pela ruptura do cotidiano em busca de uma experiência hedonística intensa do que uma procura por experiências existenciais profundas, no sentido de uma excitação no lazer através de um descontrole controlado (Elias e Dunning, 1992; Burns, 2002; Castaño, 2005). 
Essa terceira perspectiva representa uma cesura em relação à ideia essencialista da autenticidade através de uma crítica aguda às proposições de MacCannel, uma vez que, contradizendo os argumentos do autor, não só não se pode inferir empiricamente sobre o turista como um nômade espiritual ou um estruturalista arquetípico em busca do outro e do eu autênticos (MacCannel, op. cit.; Selwin, 1996) como também a busca pela autenticidade não seria condição necessária para a prática do turismo (Smith, \& Eadington, 1994; GalaniMoutafi, 2000; Peralta, 2003, Santana Talavera, Diaz Rodriguez e Rodriguez Darias, 2010).

Dito de outro modo, os turistas podem se dirigir a tal ou tal destino - e de fato o fazem majoritariamente - independentemente do apelo à autenticidade ou às idiossincrasias naturais e/ou culturais do lugar turístico, motivados muito mais por uma fruição dentro do modelo "4S" (sun, sex, sea and sand), estabelecendo um contato mínimo com a população local e apartados desta por uma "bolha ambiental" (enviromental bubble) promovida pelos brokers do sistema turístico (Cohen, 1988; Crick, 1992).

Ademais, frequentemente o turista é consciente das encenações de autenticidade promovidas localmente, e desse modo ele parece estar muito mais inclinado, como indicam Graburn \& Barthiel-Bouchier (2001) e Jafari (2007), ao gozo da estadia turística dentro de um marco ritualizado do que à sua fruição como uma atualização mítica, embora ambas perspectivas não sejam auto-excludentes.

Nesses termos, o que caracterizaria o pós-turista seriam exatamente a busca e o gozo de experiências baseadas em encenações e invenções de tradição claramente identificáveis (Burns, 2002; Pereiro, 2009; Santana Talavera, 2009; Santana Talavera, Diaz Rodriguez e Rodriguez Darias, 2010) num marco do kitsch, do pastiche ou da pura replicação de cenários que se remetem a "originais" que já seriam em si mesmos simulacros, como os caubóis tailandeses descritos por Cohen (2005).

Como consequência desse processo, a fixidez de oferta de destinos e de serviços turísticos - e das respectivas fantasias elaboradas sobre eles - será substituída nas últimas décadas do século XX por uma sofisticada politomia de corte etário (destinos e serviços preferenciais de jovens, adultos ou idosos), econômico (destinos e serviços low cost ou sofisticados) e geográfico (destinos e serviços preferidos por norte-europeus ou japoneses, por exemplo) que fluirá dentro do panorama internacional com eleições de lugares da moda em ascendência e 
obsolescência vertiginosas, com o rápido reposicionamento de destinos estabelecidos que passam a competir com uma gama de concorrentes cada vez maior, numa profunda interação entre o imaginário referente ao destino e a própria concepção do produto turístico, em função da dinâmica mesma inerente à fluidez e à adaptabilidade da atividade turística. Uma relação circular em que o olhar "estrangeiro" captura aquilo que efetivamente estava predisposto a ver, num processo semelhante ao que os antropólogos chamam, noutros contextos, de eficácia simbólica (Reilly, 1990; Nash, 1996; Silvano, 1998; Grunewald, 2002; Maoz, 2006).

\section{As Imagens do Destino Turístico}

A imagem do destino turístico ocupa uma posição privilegiada dentro das investigações sobre o turismo, especialmente por ser um objeto de interesse dos setores públicos e empresariais, configurando-se como um ponto de convergência de investigações relacionadas a áreas como marketing, administração de negócios, psicologia e economia (Mediano Serrano, 2002; Tamikawa, 2004; San Martín Gutiérrez, Rodríguez del Bosque Rodríguez, Vázquez Casielles, 2006; Das Chagas, 2008; Gândara, 2008; Figueirêdo e Mayer, 2010).

De fato, desde a década de 1970, a partir do trabalho pioneiro de Hunt, "Image: a factor in tourism", que a formação da imagem do destino (Tourism Destination Image ou TDI) vem se constituindo como um dos objetos mais investigados na área do turismo. Gallarza, Gil Saura e Calderón García (2002) indicam que até o ano de 1999 foram publicados 65 artigos sobre o tema em revistas internacionais, e Pike (2002) contabiliza pelo menos 142 trabalhos relevantes nesta temática específica entre 1973 e 2000.

Dentro do processo de formação da imagem do destino são identificados dois enfoques distintos. O enfoque estático, que investiga a relação entre a imagem e o comportamento do turista, incluindo aí focos mais delimitados, como a satisfação do turista ou a escolha do destino. E o enfoque dinâmico, que se volta para a estrutura, a formação e as transformações da imagem em si mesma no tempo (Pardellas de Blas e Padín Fabeiro, 2004; Traverso Cortés, 2004; Ryglova \& Turcinkova, 2011).

Contudo, os diversos investigadores que tratam da TDI são unânimes em afirmar que a formação de imagem do destino, além de ser definida a partir de elementos tangíveis e 
intangíveis, é necessariamente compósita, múltipla, relativa e dinâmica (Santana Talavera, 1997 e 2009; Moreno Gil, Beerli Palacio \& Martín Santana, 2004a e 2004b; López Bonilla y López Bonilla, 2007).

Ela é constituída por fontes tão distintas como a televisão, a internet, a folheteria oficial e o "marketing" boca-ouvido, e seu processo de construção inclui não só a "natureza da imagem do destino" em si mesma como também suas políticas de gerenciamento (Dann, 1996; Domínguez, Valdés \& Del Carmen Morfín, 2003; Beerli \& Martin, 2004a e 2004b).

De fato, das várias aportações conceituais sobre o tema, a maioria delas informa a natureza subjetiva da formação da imagem turística (Jenkins, 1999; Bigné, Sánchez y Sánchez, 2001; Lee, Lee \& Lee, 2005; Dolnicar \& Huybers, 2007), daí sua remissão às idéias de impressão (Echtner \& Ritchie, 1991; Milman y Pizam, 1995), percepção (Coshall, 2000; Tapachai \& Waryszak, 2000) ou representação (Leisen, 2001), tendo em conta que a imagem percebida não se confunde com sua referência física (Gartner, 1993).

A imagem do destino turístico, para Crompton (1979), é o somatório de todas as impressões, experiências, emoções e recordações que o indivíduo estabelece com o destino, portanto, seria a projeção mental que $o$ indivíduo forma em relação a um referente físico.

Baloglu \& McCleary (1999) definem a imagem como a "representação mental das crenças, os sentimentos e a impressão global do indivíduo sobre um destino turístico”. Esta definição extensiva comporta tanto as bases de conhecimento, valores e crenças, definidas tradicionalmente pela literatura especializada (Baloglu \& Brinberg, 1997; Baloglu, 1999), quanto as disposições afetivas, elemento incorporado mais recentemente nas discussões sobre o tema (Kim \& Richardson, 2003; Pike \& Ryan, 2004).

Desse modo, a explicitação das dimensões simultaneamente cognitiva e afetiva no campo dos estudos sobre a imagem do destino turístico possibilita uma avaliação não só mais abrangente como também mais próxima da própria natureza compósita da imagem.

Nesse sentido, a escolha do destino compreenderia três dimensões bem definidas: (a) uma avaliação racional baseada nos atributos percebidos, marcada por caracteres cognitivos ligados ao nível de conhecimento e aos estereótipos formados sobre o lugar; (b) uma interpretação emocional fundada numa perspectiva afetiva; e (c) um enfoque global com a 
valoração geral do destino, incluindo aí os traços culturais locais, o entorno social, os recursos naturais, a infra-estrutura material, o entorno político e econômico, ócio noturno e opções de compras (Moreno Gil, Beerli Palacio e Martín Santana, 2004a). Portanto, a formação da imagem seria derivada tanto de fatores pessoais quanto externos ao indivíduo (Baloglu e McCleary, op. cit, 870):

\section{$\Gamma$ Psicológicos $\rightarrow$ valores, motivacionais, personalidade}

- Fatores pessoais (internos)

$\hookrightarrow$ Sociais $\rightarrow$ Idade, educação, estado civil, outros

$\Gamma$ Fontes de informação $\rightarrow$ quantidade e tipo

- Fatores estimulo (externos) $\rightarrow$ experiência prévia

\section{$\hookrightarrow$ Distribuição}

Figura 1 - Fatores de formação da imagem turística Fonte: Baloglu e McCleary, 1999.

Os autores sugerem o isolamento de algumas variáveis que seriam determinantes na formação e percepção da imagem turística a partir do ponto de vista do turista, tais como variedade (quantidade) de fontes de informação, tipo de fontes de informação, idade, nível de educação formal e motivações sócio-psicológicas para viajar. Esses elementos seriam alguns dos fatores-chave para a decisão de compra de tal ou tal pacote turístico.

Assim, embora o marco geográfico seja importante na configuração da imagem-destino, esta tende a se projetar sobre a correspondente física, mesclando-se ao apelo do marketing e às experiências anteriores do turista potencial, inclusive considerando que, embora muitos destinos possam dispor de serviços similares, em geral eles apresentam imagens ou marcas distintas entre si (Gallarza, Gil Saura e Calderón García, 2002; López Bonilla e López Bonilla, 2007). 
Desse modo, a imagem do lugar turístico englobaria, do ponto de vista do turista, a imagemidentidade do lugar como correspondente físico e seus atributos funcionais e psicológicos (Gândara, 2008). É nesse contexto que se pode pensar no destino como um macro-produto territorial (Borja Solé, Casanovas Pla e Bosch Camprubí, 2002), isto é, uma entidade territorial percebida como uma unidade onde se pode encontrar destinos menores diferenciados entre si.

Segundo López Bonilla e López Bonilla (2007), o produto turístico compõe-se de (a) produto genérico, isto é, os atrativos naturais e artificiais; (b) o produto esperado, os bens e serviços turísticos básicos, ou seja, sua infraestrutura material; e (c) o produto melhorado, que seria o conjunto das "vantagens" adicionais, como a hospitalidade e a relação qualidade-preço.

De um modo geral a literatura especializada utiliza a "teoria das sete fases" (figura 2) ou modelo de Gunn (Gunn, 1972; Fakeye and Crompton, 1991) para descrever o circuito de formação da imagem turística (Chon, 1990 e 1991; Traverso Cortés, 2004):

\section{Acumulação de imagens mentais} sobre experiências de férias

\section{Imagem original}

2. Modificação destas imagens por novas informações

\section{Imagem induzida}

\section{Decisão de sair de férias}

4. Viagem ao destino

5. Participação no destino Imagem modificada

6. Viagem de regresso

7. Nova acumulação de imagens baseadas na experiência

Figura 2 - Esquema das sete fases de Gunn Fonte: Baseado em Gunn, 1972; Chon, 1990 e 1991; Fakeye and Crompton, 1991

Nessa perspectiva, a imagem induzida seria uma ampliação quantitativa e qualitativa da imagem original ou orgânica, resultado do acúmulo de informações advindas de várias fontes 
como livros, revistas, jornais, comentários de amigos ou parentes, capturadas na ambiência social donde se inscreve o futuro turista. A imagem induzida, nesse contexto, refere-se àquela promovida pelo destino e/ou tour-operadores com o intuito de atrair o visitante. Considerando as proposições de Dann (1977) e Crompton (1979a e 1979b), enquanto que a imagem original estaria alocada no âmbito dos fatores de estímulo (push), a imagem induzida se inscreveria como fator de indução (pull), isto é, de atração do turista potencial.

Portanto, esta última seria estratégica para o destino, uma vez que representa o momento crítico de escolha do turista, considerando que o produto turístico só é consumido após uma minuciosa seleção prévia, onde se crê que o viajante, antes de assumir o risco do eleger um destino - que afinal é um produto que não pode ser provado ou testado antes da compra -, tente minimizá-lo munindo-se de todas as informações que lhe esteja disponível, além de sopesar as possibilidades de destinos alternativos, conforme seu interesse e motivação (Moutinho, 1987; Goodall, 1991; Kent, 1991; Bigné y Sánchez, 2001).

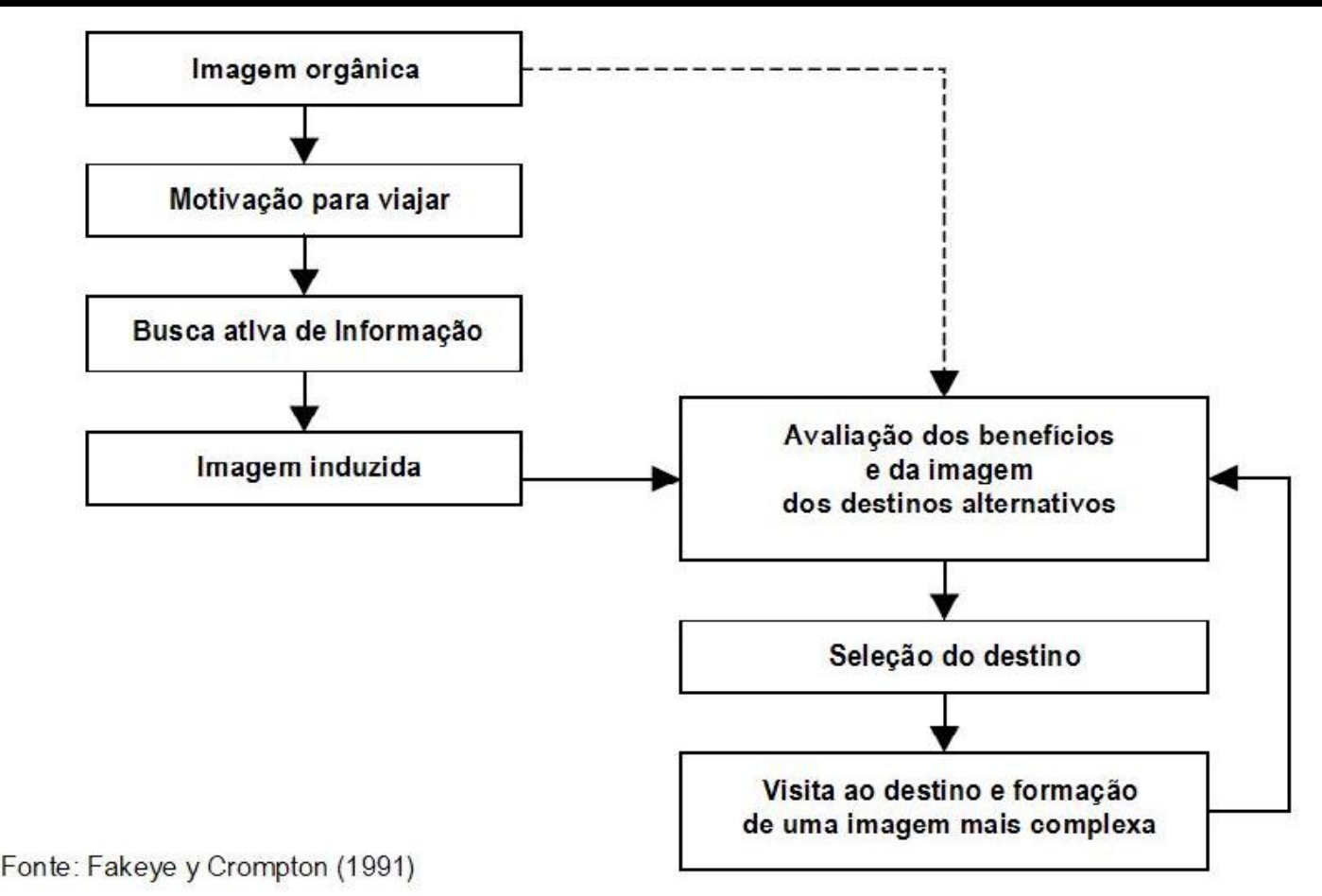

Figura 3 - Modelo de Fakeye y Crompton (1991) da formação da imagem turística 
Uma vez no destino, o turista irá confrontar a imagem que havia previamente desenhado na sua mente com o que de fato estará vivenciando (figura 3). De acordo com alguns autores, a satisfação do turista é diretamente proporcional à proximidade entre sua imagem prévia do lugar e a realidade experienciada (Chon, 1990, 1991 e 1992b). Portanto, após sua estadia o turista comporá, segundo Fakeye y Crompton (1991), a imagem complexa do destino (ou modificada, em Gunn), resultante do contraste entre as imagens formadas antes da viagem e sua avaliação após a visita ao destino.

Considerando a natureza fugidia da imagem, Echtner y Ritchie (1993) decompõem-na, num modelo tridimensional, em três contínuos bipolares (figura 4): a. atributo-holístico; b. funcional-psicológico; c. comum-único. No âmbito do binômio atributo-holístico, indica-se que a imagem se compõe não apenas de caracteres isolados (como largamente se vê na literatura especializada), mas sim de uma dimensão holística do lugar. O binômio funcionalpsicológico se relaciona às percepções tangíveis (funcionais) ou abstratas (psicológicas). $\mathrm{O}$ contínuo comum-único se refere à constatação de que tanto as percepções holísticas ou fragmentadas em atributos podem ser comuns para todos os destinos ou únicas para cada um deles. O componente único representa um ponto importante para a imagem do destino na medida em que pressupõe um elemento singularizador frente a outros destinos. Desse modo, há que considerar que, por ser multifoliada e multidimensional, uma interpretação sobre a imagem do lugar deve considerar as co-relações entre todos os componentes identificados pelos autores. 


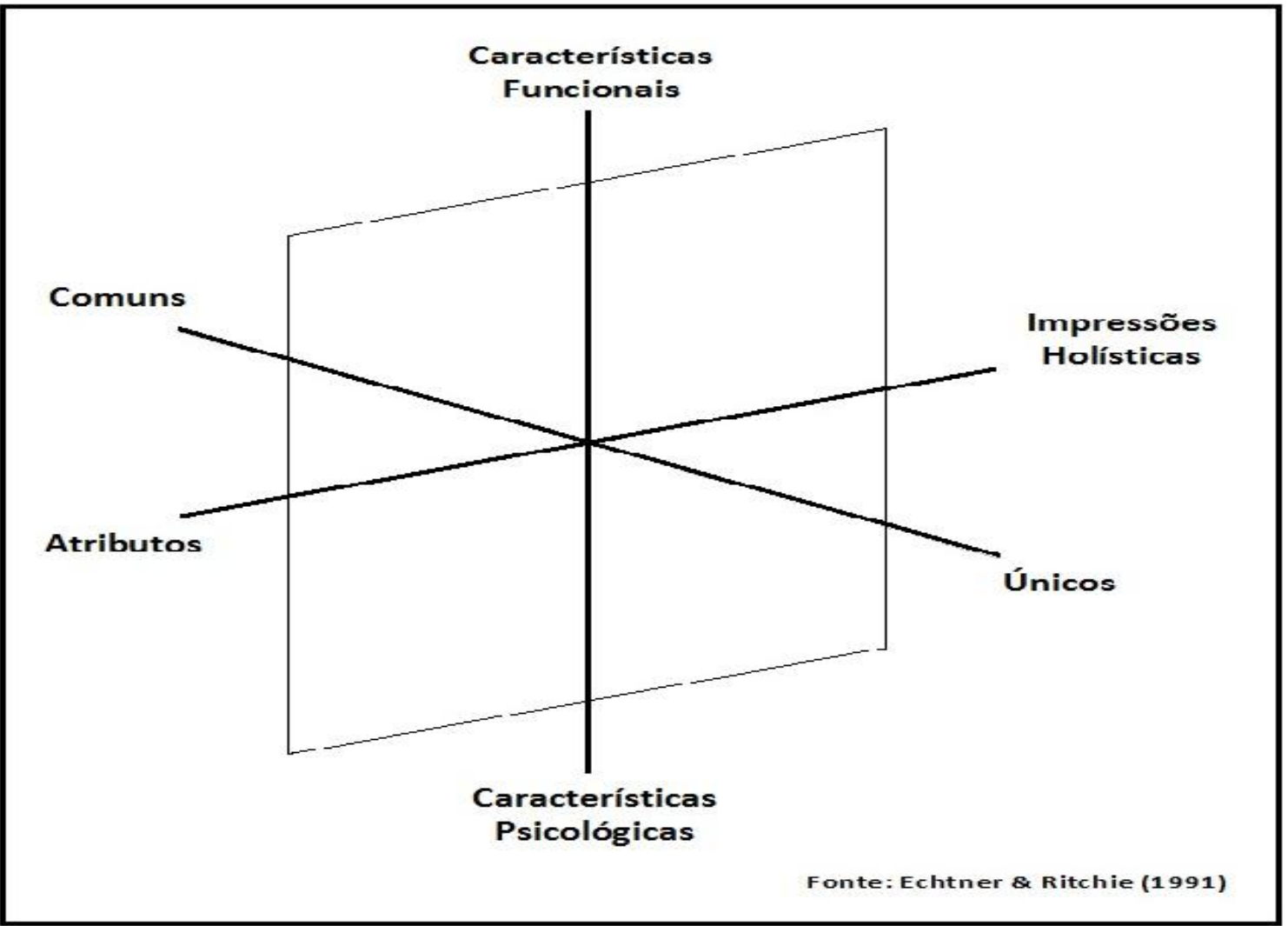

Figura 4 - Modelo relativo às componentes da imagem turística Fonte: Baseado em Echtner \& Ritchie (1991).

Segundo indicam San Martín Gutiérrez, Rodríguez del Bosque Rodríguez e Vázquez Casielles (2006), em geral as investigações sobre o tema têm se concentrado no componente comum da imagem, desconsiderando, portanto, as dimensões holística e única. Do mesmo modo, tem-se enfatizado a estrutura cognitiva subjacente ao conjunto de atributos ligados à componente comum, especialmente fatores do entorno natural, os recursos culturais e as infraestruturas turísticas, em detrimento das demais.

\section{Novo Prisma Sobre a Formação das Imagens no Turismo: uma proposta holística}

Em que pese a inegável importância das investigações relacionadas à TDI para o entendimento do turismo como um todo, tanto no que se refere aos avanços teóricos quanto à pesquisa aplicada, nota-se, no conjunto dos trabalhos, um viés fortemente economicista e 
psicologizante, com as investigações sendo enfocadas quase que exclusivamente na figura do turista - e este, isolado do seu entorno econômico e sócio-cultural -, caracterizado como uma unidade discreta do Homo economicus, individualista, racional, pragmático, maximizador de benefícios e minimizador de prejuízos.

Nesta perspectiva, conformada segundo o lastro da economia clássica, a sociedade seria o agregado de consciências autocentradas e independentes, com cada indivíduo atomizado buscando realizar seus desejos e impulsos através de infindáveis cálculos utilitaristas.

Ora, esse modelo incorre em três problemas de natureza teórico-conceitual, situados em níveis distintos: (1) em primeiro lugar, ele subestima o peso dos constrangimentos e disposições socioculturais definidos pela sociedade de origem do turista-consumidor; (2) os destinos turísticos não são necessariamente "intercambiáveis", posto que especialmente os destinos maduros possuem imagens estabelecidas e singularizadas cujos atributos não admitem parâmetro de comparação ${ }^{3}$; e, num nível mais amplo, (3) no mundo social o consumo vicário divide espaço necessariamente com elementos que não são totalmente monetarizáveis ou não são "negociáveis", como a reputação, a imagem pessoal, a carreira, a família, etc. (Shils, 1992; Douglas \& Isherwood, 2004) ${ }^{4}$.

Portanto, há que considerar que o cálculo racional-consumista se efetua dentro de uma arena maior, onde o que está em jogo é a integridade social de cada indivíduo, num mundo em que nem tudo pode ser comprado e que os valores atribuídos aos bens, serviços e experiências não são idênticos para todas as pessoas, mas sim que dependem de uma complexa combinação de fatores socioeconômicos que, por sua vez, estarão inscritos nos parâmetros culturais mais amplos de cada sociedade (Bourdieu, 1974 e 1979).

Essa perspectiva, dentro do turismo, poderia ser avaliada contrastando, por exemplo, a relação entre a posição de status do turista em sua sociedade de origem e seus critérios de avaliação de um destino turístico. Ou como a percepção de um destino pelos seus residentes afeta a

\footnotetext{
${ }^{3}$ Por exemplo, embora a Torre Eiffel e a Estátua da Liberdade sejam ícones, respectivamente, de Paris e Nova Iorque, elas se igualam apenas neste sentido funcional de evocação do lugar específico em que se situam, uma vez que seus atributos físicos e, sobretudo simbólicos, tanto em termos absolutos quanto relativos, são únicos, de forma que não permitem parâmetros de comparação entre si.

${ }^{4}$ No campo do turismo isto incide diretamente na escolha do destino, tanto na convergência do estilo de vida do turista com a eleição do local a se visitar, quanto, especialmente, no rechaço de visitas a ambiências que este turista julgue de antemão "inadequadas" à sua reputação ou imagem pessoal.
} 
percepção do destino do turista. Ou ainda como a imagem promovida afeta a própria percepção territorial dos residentes.

De fato, como indicam Coles, Duval e Hall (2005, 86 e 98), os turistas devem ser entendidos como sujeitos cujas formas de turismo partem de uma rotina mais complexa, devendo-se considerar o Homo touristicus não como um ente isolado econômica e socialmente, mas como um indivíduo inscrito num contexto sociocultural muito mais amplo.

Além disso, o modelo hegemônico da TDI não só oferece uma figuração limitada do turista (derivada de um viés da economia, do marketing e da administração de negócios, donde majoritariamente advêm os autores que tratam da formação da imagem turística), como também praticamente desconsidera a importância de outras imagens do destino, que são elaboradas e reelaboradas por diversos atores envolvidos direta e indiretamente no sistema turístico, especialmente nos processos de concepção, formação e veiculação da imagem turística, e que também vão compor mais difusamente o imaginário do lugar como um todo.

Nesse sentido, a maioria dos investigadores ligados à TDI acaba não só por sub-dimensionar a importância dos atributos culturais das sociedades emissoras e receptoras como também imprime uma visão hipo-socializada do processo de formação da imagem turística, perdendose a dimensão simbólica (portanto, fundamentalmente coletiva) que embebe a prática do turismo, a viagem em si mesma, e a conformação do destino, desconsiderando-se, por um lado, que o espaço turístico está contido num território não-turístico a princípio, que obedece à sua própria dinâmica sociocultural e, por outro lado, que a individualidade do turista é componente e resultante de um quadro mais amplo de natureza social e cultural (Goffman, 1959; Pais, 1996; Castaño, 2005; Santana Talavera, 2009).

Assim, deixa-se de lado todo o processo de construção da identidade do destino, tanto a partir do ponto de vista da sociedade emissora quanto da receptora, olvidando-se que ambas elaboram estereótipos e pré-concepções (de si e do outro) a partir de pautas culturais inscritas numa dinâmica dialógica, segundo fatores como os fluxos informacionais/comunicacionais mais amplos, os modismos, o efeito demonstração, ou mesmo as disposições hierárquicas e de poder nos planos local, regional, nacional e internacional (Barretto, 2000 e 2003; Burns, 2002; Pinto, 2002 e 2006). 
Nesse sentido, cada sociedade receptora imprime ao território turístico e ao seu entorno uma unicidade simbólica dentro de um quadro interpretativo polifônico, que será o lastro informacional para o estabelecimento das relações entre o "nós" e o "eles", operando traços distintivos por oposição e aproximação: turistas-locais, locais-locais, turistas-turistas (Barretto, 2007 e 2010; Pereiro, 2009; Santana Talavera, 2009).

Assim, pensando em termos de um enfoque sistêmico processual, levando em conta os avanços da literatura especializada e incorporando as devidas críticas, pode-se estabelecer, para além de uma concepção unidirecional limitada ao turista, um modelo alternativo de formação da imagem do destino turístico cuja imagem global se conecta a imagens parciais desenvolvidas pelos diversos atores que interatuam no campo turístico.

E que, ao mesmo tempo, possa distinguir não só os processos de concepção, desenho e ativação dos elementos que conformam a imagem construída para venda, como também seus princípios e dispositivos de percepção e introjeção, tanto para os atores que operam no destino quanto para os visitantes (quadro 1): trata-se, como ressalta Santana Talavera (2007), “de abrir os esquemas e modelos de investigação a uma dupla vertente de processos retroalimentados e interconectados que metodologicamente permitam um estudo por etapas, com indicadores válidos em cada uma delas." 
Quadro 1- Modelo geral das imagens no turismo (criação, consumo e recriação)

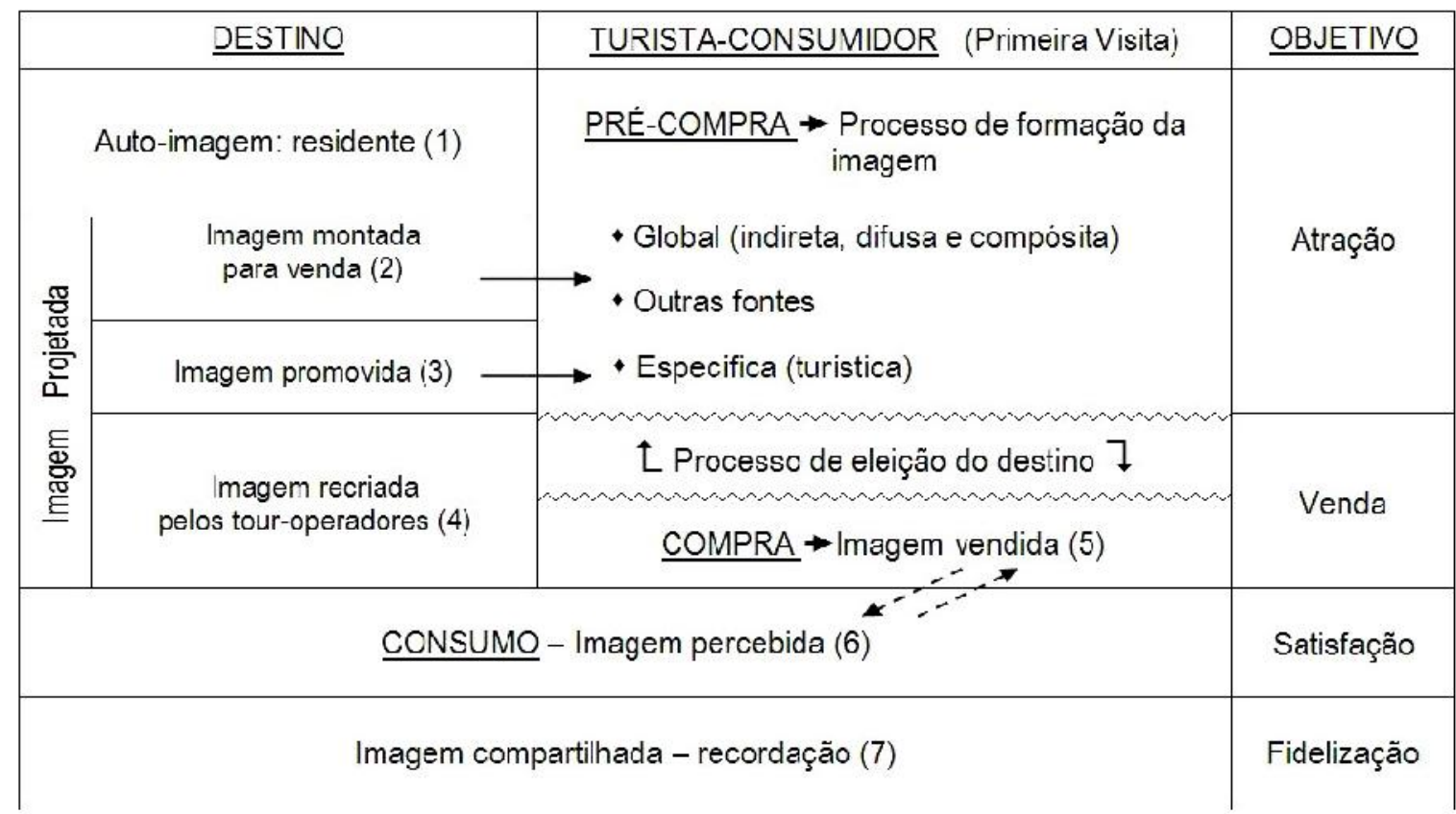

$\begin{array}{lllllllllllllllllllll} & \uparrow \uparrow & \uparrow & \uparrow \uparrow & \uparrow \uparrow & \uparrow \uparrow & \uparrow \uparrow & \uparrow \uparrow & \uparrow \uparrow & \uparrow \uparrow & \uparrow \uparrow & \uparrow \uparrow & \uparrow \uparrow & \uparrow \uparrow & \uparrow \uparrow & \uparrow \uparrow & \uparrow \uparrow & \uparrow \uparrow & \uparrow \uparrow & \uparrow \uparrow\end{array}$

\section{$\lceil$ Processo retro-alimentado $\beth$}

Determinação de controles, mudanças na demanda, adaptaçães do produto, redução de efeitos, etc.

Fonte: Baseado em Santana Talavera \& Pinto, 2008.

O modelo aqui proposto se desdobra em sete sub-processos distintos e inter-relacionados entre si, e cujos limites muitas vezes são fugidios no campo empírico. Contudo, seu desenho permite não só distinguir cada um destes processos, como investigá-los tanto isoladamente quanto dentro do conjunto mais amplo da formação da imagem, uma vez que as resultantes parciais de cada sub-processo, ao mesmo tempo em que refletem o ponto de vista dos atores sociais que as conforma, definem a partir de que ponto do processo mais geral elas são criadas e/ou recriadas.

Assim, segundo a proposição deste modelo geral de imagens turísticas, tem-se, conforme o disposto no quadro 1, a auto-imagem local ou imagem residente (1), isto é, o conjunto de disposições identitárias locais que definiriam, por associação e contraste, os traços diacríticos mais importantes de uma dada comunidade. A partir desta matriz representacional seriam 
elaboradas pelos gestores públicos e privados a (2) imagem montada para venda, a (3) imagem promovida e (4) a imagem recriada pelos tour-operadores, que conjuntamente vão compor a imagem projetada, desenhada para a promoção turística e re-apropriada pelos diversos intermediários do sistema como um todo (brokers), especialmente as operadoras turísticas. Esta imagem formatada será capturada pelo turista enquanto (5) imagem vendida, que por seu turno será contrastada com a (6) imagem percebida no destino, quando da fruição da estadia turística. Ao regressar à sua sociedade de origem, o turista irá difundir a (7) imagem compartilhada, resultante da comparação entre as imagens projetada, vendida e percebida, retroalimentando o sistema especialmente através de dispositivos midiáticos, com especial ênfase na internet.

\section{Considerações Finais}

Desse modo, seccionando o processo de formação da imagem do destino, por um lado, e por outro lado, ampliando seu horizonte analítico - ao congregar os pontos de vista dos múltiplos atores inseridos no sistema turístico como um todo, e não apenas o olhar do turista - , tem-se um quadro que permite reconstruir a imagem turística numa perspectiva holística e processual.

Assim, o modelo proposto mostra-se útil no campo da investigação ao incorporar às etapas de criação, consumo e recriação da imagem turística, atores e pontos de vista - em geral desconsiderados na TDI - interconectados com a auto-imagem residente ou os vários tipos de brokers (tour-operadores, profissionais de marketing, imprensa...), além de relacionar as várias fases do processo aos olhares múltiplos sobre o lugar, situando simultaneamente os vários agentes envolvidos no sistema.

Com isso, ao enfocar imagens contrastantes e até mesmo conflituosas entre si dentro da perspectiva multidimensional onde as sociedades (e as imagens) se movem, tem-se uma proposta mais realista do processo de formação da imagem turística, dentro de uma representação heterogênea que a aproxima a um modelo mais condizente com a polifonia própria às animações da vida social. 


\section{Referências}

APPADURAI, A. Global Ethnoscapes: Notes and Queries for a Transnational Anthropology. In: FOX, R. (Ed.). Recapturing Anthropology: Working in the Present. Santa Fe: School of American Research Press, 1991. P. 191- 210.

APPADURAI, A. The Production of Locality. In: R. Fardon (ed.). Counterworks. London: Routledge, 1995.

AUGÉ, M. El Viaje Imposible: el turismo y sus imágenes. Barcelona: Gedisa, 1998.

AUGÉ, M. Rapports Entre Tourisme, Culture et Territoire. Turisme i Cultura. Debats del Congrés de Turisme Cultural. Saló Internacional del Turismo a Catalunya. Barcelona: Fundació Interarts, 2001. P. 21-31.

BALOGLU, S. A Path Analytic Model of Visitation Intention Involving Information Sources, SocioPsychological Motivations, and Destination Image. Journal of Travel \& Tourism Marketing, 8(3), 1999. P. 81-91.

BALOGLU, S. Image Variations of Turkey by Familiarity Index: Informational and Experiential Dimensions. Tourism Management, 22(2), 2001. P. 127-133.

BALOGLU, S. \& BRINBERG, D. Affective Images of Tourism Destinations. Journal of Travel Research, 35(4), 1997. P. 11-15.

BALOGLU, S. \& MANGALOGLU, M. Tourism Destinations Images of Turkey, Egypt, Greece, and Italy as Perceived by US-Based Tour Operators and Travel Agents. Tourism Management, 22(1), 2001. P. 1-9.

BALOGLU, S. \& MCCLEARY, K. W. A Model of Destination Image Formation. Annals of Tourism Research, 26(4), (1999). P. 868-897.

BARRETTO, M. As Ciências Sociais Aplicadas ao Turismo. In: SERRANO, C., BRUHNS, H. e LUCHARI, M. (Orgs.). Olhares Contemporâneos sobre o Turismo. Campinas: Papirus, 2000.

BARRETTO, M. O Imprescindível Aporte das Ciências Sociais para o Planejamento e a Compreensão do Turismo. Horizontes Antropológicos, a. 9, n. 20, 2003. P. 15-29.

BARRETTO, M. Turismo y Cultura. Relaciones, Contradicciones y Expectativas. El Sauzal: PASOS, Revista de Turismo y Patrimonio Cultural. E-book, Colección Pasos Edita no 1, 2007. Disponível em: http://www.pasosonline.org/Paginas/e-book.htm. Acesso em 21 mar. 2009.

BARRETTO, M. (Ed.). Turismo, reflexividad y procesos de hibridación cultural en América del Sur austral. El Sauzal: PASOS, Revista de Turismo y Patrimonio Cultural. E-book, Colección Pasos Edita $n^{\circ}$ 4, 2010. Disponível em: http://www.pasosonline.org/Paginas/e-book.htm. Acesso em 09 jan. 2011.

BEERLI, A. \& MARTÍN, J. D. Tourists' Characteristic and the Perceived Image of Tourist Destinations: A Quantitative Analysis - A Case Study of Lanzarote, Spain. Tourism Management, 25(5), 2004a. P. 623-636.

BEERLI, A. \& MARTIN, J. D. Factors Influencing Destination Image. Annals of Tourism Research, 31 (3), 2004b. P.657-681.

BIGNÉ, J. E. y SÁNCHEZ, M. I. Evaluación de la Imagen de destinos turísticos: Una aplicación metodológica en la Comunidad Valenciana. Revista Europea de Dirección y Economía de la Empresa, 10(3), 2001. P. 189-200.

BIGNÉ, J. E., SÁNCHEZ, M. I. and SÁNCHEZ, J. Tourism Image, Evaluation Variables and After Purchase Behaviour: Inter-Relationship. Tourism Management, 22(6), 2001. P. 607-616. 
BOORSTIN, D. The Image: A guide to pseudo events in America. New York: Harper \& Row, 1961.

BORJA SOLÉ, L., CASANOVAS PLA, J. A. y BOSCH CAMPRUBÍ, R. El Consumidor Turístico. ESIC Editorial: Madrid, 2002.

BOURDIEU, P. A Economia das Trocas Simbólicas. São Paulo: Perspectiva, 1974.

BOURDIEU, P. La Distinction : Critique Sociale du Jugement. Paris: Les Éditions de Minuit, 1979.

BURNS, P. Turismo e Antropologia: uma introdução. São Paulo: Chronos, 2002.

CASTAÑO, J. M. Psicología Social de los Viajes y del Turismo. Madrid: Thompson, 2005.

CHAMBERS, E. Native Tours: The Anthropology of Travel and Tourism. Long Grove: Waveland Press, 2000.

CHON, K-S. The role of destination image in tourism: a review and discussion. Revue du tourisme, 47(2), 1990. P. 2-9.

CHON, K-S. Tourism Destination Image Modification Process: Marketing Implications. Tourism Management, 12(1), 1991. P. 68-72.

CHON, K-S. The Role of Destination Image in Tourism: An Extension. The Tourist Review. The Journal of the International Association of Scientific Experts in Tourism, 43(1), 1992. P. 2-8.

CHON, K-S. \& OLSEN, M. Functional and Symbolic Congruity Approaches to Consumer Satisfaction/Dissatisfaction in Tourism. Journal of the International Academy of Hospitality Research. Issue 3, 1991. P. 2-22.

COHEN, E. Towards a Sociology of international tourism. Sociological Research, 39, 1972. P. 164182.

COHEN, E. Rethinking the sociology of tourism. Annals of Tourism Research, 6, 1979. P. 18-35.

COHEN, E. Authenticity and Commoditisation in Tourism. Annals of Tourism Research, 15, 1988. P. 371-386.

COHEN, E. Principales Tendencias en el Turismo Contemporáneo. Política y Sociedad, 42(1), 2005. P. 11-24.

COLES, T., DUVAL, D., HALL, M. Sobre el Turismo y la Movilidad en Tiempos de Movimiento y Conjetura Posdisciplinar. Política Y Sociedad, vol. 42, n. 1, 2005. P. 85-99.

CROMPTON, J. Motivations for pleasure vacations. Annals of Tourism Research, 6, 1979a. P. 408424.

CROMPTON, J. An assessment of the image of Mexico as a vacation destination and the influence of geographical location upon that image. Journal of Travel Research, 17(1), 1979b. P. 18-23.

COSHALL, J. T. "Measurement of Tourists' Images: The Repertory Grid Approach. Journal of Travel Research, 39(1), 2000. P. 85-89.

CRICK, M. Representaciones del turismo internacional en las ciencias sociales: sol, sexo, paisajes, ahorros y servilismos. In: JURDAO ARRONES, F. (Comp). Los Mitos del Turismo. Madrid: Endimión, 1992. P. 339-404.

DANN, G. Anomie, ego-enhancement and tourism. Annals of Tourism Research, 4, 1977. P. 184-194.

DANN, G. Tourists' Images of a Destination - An Alternative Analysis. Journal of Travel \& Tourism Marketing, 5(1-2), 1996. P. 41-55. 
Das CHAGAS, M. Imagem de destinos turísticos: uma discussão teórica da literatura especializada. Revista Turismo Visão e Ação, v. 10, $\mathrm{n}^{\circ}$ 03, p. 435-455, 2008. Disponível em: www.univali.br/revistaturismo, Acesso em: 12 mar. 2011.

DOLNICAR, S. \& HUYBERS, T. Different Tourists - Different Perceptions of Different Places: Accounting for Tourists' Perceptual Heterogeneity in Destination Image Measurement. Tourism Analysis, v. 12, 2007. P. 447-461.

DOMÍNGUEZ, P., VALDÉS, R. y Del CARMEN MORFÍN, M. Los Medios de Comunicación y su Impacto en la Formación de la Imagen de un Destinto Turístico: La Opinión del Mercado Europeo Sobre México. XIII Simposio Internacional de Turismo y Ocio. ESADE - Fira de Barcelona, 2003.

DOUGLAS, M. e ISHERWOOD, B. O Mundo dos Bens: para uma antropologia do consumo. Rio de Janeiro: UFRJ, 2004.

ECHTNER, C. M. \& RITCHIE, J. R. The Meaning and Measurement of Destination Image. The Journal of Tourism Studies, 2(2), 1991. P. 2-12.

ECHTNER, C. M. \& RITCHIE, J. R. The Measurement of Destination Image: An Empirical Assessment. Journal of Travel Research, 31(4), 1993. P. 3-13.

ELIAS, N. e DUNNING, E. A Busca da Excitação. Lisboa: Difel, 1992.

EKINCI, Y. e HOSANY, S. Destination Personality: An Application of Brand Personality to Tourism Destinations. Journal of Travel Research, n. 45, 2006. P. 127-139.

FAKEYE, P. C. \& CROMPTON, J. L. Image Differences between Prospective, First-Time and Repeat Visitors to the Lower Rio Grande Valley. Journal of Travel Research, 30(2), 1991. P. 10-16.

FEATHERSTONE, M. Postmodernism, Cultural Change and Social Pratice. In: KELLNER, D. Postmodernism/Jameson/Critique. Maisonneuve: Washington, 1989.

FEATHERSTONE, M. Cultura de consumo e pós-modernismo. São Paulo: Studio Nobel, 1995.

FIGUEIRÊDO, A. e MAYER, V. A Imagem dos Destinos Turísticos: a cidade de São Paulo sob o olhar de jovens do Rio de Janeiro. Turismo em Análise, v. 21, n. 3, 2010. P. 445-469.

GALANI-MOUTAFI, V. The self and the other. Traveler, ethnographer, tourist. Annals of Tourism Research, 27 (1), 2000. P. 203-224.

GOODALL, B. Opportunity set concept: An application to tourist destination areas. In: ASWORTH, G. \& GOODALL, B. Marketing Tourism Places. Routledge: London, 1991.

GALLARZA, M. G., GIL SAURA, I. and CALDERÓN GARCÍA, H. Destination Image: Towards a conceptual framework. Annals of Tourism Research, 29 (1), 2002. P.56-78.

GÂNDARA, J. M. A Imagem dos destinos turísticos urbanos. Revista Eletrônica de Turismo Cultural, Número Especial, 2008. P. 1-22. Disponível em: www.eca.usp.br/turismocultural/aimagem.pdf. Acesso em: 14 abr. 2011.

GARTNER, W. C. Image Formation Process. Journal of Travel \& Tourism Marketing, 2(2/3), 1993. P. 191-215.

GOFFMAN, E. The Representation of Self in Everyday Life. New York: Doub, 1959.

GRABURN, N. \& BARTHIEL-BOUCHER, D. Relocating the Tourist. International Sociology, 16(2), 2001. P. 147-158. 
GRENNWOOD, D. Culture by the Pound. An Anthropological Perspective on Tourism as a Cultural Commoditization. In: SMITH, V. (coord.). Hosts and Guests: The Anthropology of Tourism. Philadelphia: University of Pennsylvania Press, 1977. P. 129-138.

GRÜNEWALD, R. Tourism and Cultural Revival. Annals of Tourism Research, 29(4), 2002. P. 10041021.

GUNN, C. Vacationscape. Designing tourist regions. Washington, DC: Taylor and Francis/University of Texas, 1972.

JAFARI, J. Modelos del turismo: los aspectos socioculturais. In: LAGUNAS, D. (Coord.). Antropología y Turismo. Claves Culturales y Disciplinares. México, D. C.: Plaza y Valdés, 2007. P. 47-71.

JENKINS, O. H. Understanding and Measuring Tourist Destination Images. International Journal of Tourism Research, 1, 1999. P. 1-15.

KENT, P. People, places, and priorities: Opportunity sets and consumer's Holiday Choice. In: ASWORTH, G. \& GOODALL, B. Marketing Tourism Places. Routledge: London, 1991.

KIM, H. \& RICHARDSON, S. Motion Picture Impacts on Destination Images. Annals of Tourism Research, 30(1), 2003. P. 216-237.

LAGUNAS, D. (Coord.). Antropología y Turismo. Claves Culturales y Disciplinares. México, D. C.: Plaza y Valdés, 2007.

LASH, S. \& URRY, J. Economies of Signs and Space. London: Sage, 1994.

LEE, C-K.; LEE, Y-K. and LEE, B. K. Korea's Destination Image Formed By the 2002 World Cup. Annals of Tourism Research, 32(4), 2005. P. 839-858.

LEISEN, B. Image Segmentation: The Case of a Tourism Destination. Journal of Services Marketing, 15(1), 2001. P. 49-66.

LÓPEZ BONILLA, J. M. y LÓPEZ BONILLA, L. M. Diferencias Territoriales en la Planificación y la Gestión del Destino Turístico. Cuadernos de Turismo, n. 19, 2007. P. 71-90.

LÓPEZ LARA, E. La Imagen Turística de Marruecos Proporcionada por Internet: Reinterpretando el Orientalismo. Cuadernos de Turismo, n. 16, 2005. P. 123-134.

MACCANNELL, D. The tourist: A new theory of the leisure class. Londres: Macmillan, 1976.

MACCANELL, D. El turista. Una Nueva Teoría de la Clase Ociosa. Barcelona: Melusina, 2003.

MAOZ, D. The Mutual Gaze. Annals of Tourism Research, 33 (1), 2006. P. 221-239.

MARTÍN DE LA ROSA, B. La Imagen turística de las regiones insulares: las islas como paraísos. Cuadernos de Turismo, n. 11, 2003. P. 127-137.

MEDIANO SERRANO, L. Incidencia del Nuevo Consumidor Turístico en la Estrategia de Marketing. Revista de Dirección y Administración de Empresas. Enpresen Zuzendaritza eta Administraziorako Aldizkaria, 2002. N. 10. P. 99-117.

MILMAN, A. \& PIZAM, A. The Role of Awareness and Familiarity with a Destination: The Central Florida Case. Journal of Travel Research, 33(3), 1995. P. 21-27.

MORENO GIL, S., BEERLI PALACIO, A. e MARTÍN SANTANA, J. (2004a). La Concepción Sistémica De La Imagen Del Destino: Una Aproximación Desde La Imagen Del Alojamiento. XIII Simposio Internacional de Turismo y Ocio, Barcelona, 21 y 22 de abril de 2004. 
MORENO GIL, S., BEERLI PALACIO, A. e MARTÍN SANTANA, J. La Imagen de Gran Canaria como destino turístico. Vector plus: miscelánea científico - cultural, n. 23, 2004. P. 71-78.

MOUTINHO, L. Consumer behaviour in tourism. European Journal of Marketing, 21(10), 1987. P. 344.

NASH, D. Anthropology of Tourism. New York: Pergamon, 1996.

PAIS, J. M. Das regras do método, aos métodos desregrados. Tempo Social - Revista de Sociologia da USP, São Paulo, 8(1), 1996. P. 85-111.

PARDELLAS de BLAS, X., PADIN FABEIRO, C. La Formación de la imagen de un nuevo destino. XIII Simposio Internacional de Turismo y Ocio. ESADE - Fira de Barcelona, 2004.

PEARCE, P. L. The Social psychology of tourism behaviour. Oxford: Pergamon Press, 1982.

PERALTA, E. O Mar Por Tradição: O Património e a Construção das Imagens do Turismo. Horizontes Antropológicos, 9(20), 2003. P. 83-96.

PEREIRO, X. Turismo Cultural. Uma Visão Antropológica. El Sauzal: PASOS, Revista de Turismo y Patrimonio Cultural. E-book, Colección Pasos Edita $\mathrm{n}^{\mathrm{o}}$ 2, 2009. Disponível em: http://www.pasosonline.org/Paginas/e-book.htm. Acesso em 10 fev. 2010.

PIKE, S. Destination Image Analysis - A review of 142 papers from 1973-2000. Tourist Management. 23(5), 2002. P. 541-549.

PIKE, S. \& RYAN, C. Destination Positioning Analysis Through a Comparison of Cognitive, Affective, and Conative Perceptions. Journal of Travel Research, 42(4), 2004. P. 333-342.

PINTO, R. Fábrica de tradiciones. Salvador, Brasil. Revista Estudios y Perspectivas en Turismo, v. 11, n. 1 y 2, 2002. P. 103-122.

PINTO, R. Turismo e Identidade: A Gestão da Baianidade e a Produção de Tradições. Caxias do Sul: Educs, 2006.

PINTO, R. e PEREIRO, X. Turismo e Antropologia: contribuições para um debate plural. Revista Turismo \& Desenvolvimento, n. 13/14, p. 447-454, 2010.

REILLY, M. D. Free Elicitation of Descriptive Adjectives for Tourism Image Assessment. Journal of Travel Research, 28(4), 1990. P. 21-26.

REISINGER, Y. E STEINER, C. Reconceptualizing Object Authenticity. Annals of Tourism Research, 33(1), 2005. P. 65-86.

RYGLOVA, K. \& TURCINKOVA, J. Image as an Important Factor of Destination Management. Working Papers of the Finnish Forest Research Institute 2. Disponível em: http://www.metla.fi/julkaisut/workingpapers/2004/mwp002.htm, Acesso em: 14 abr. 2011.

SAN MARTÍN GUTIÉRREZ, H., RODRÍGUEZ Del BOSQUE RODRÍGUEZ, I. y VÁZQUEZ CASIELLES, R. Análisis de la Imagen en Turismo Mediante Técnicas Estructuradas y no Estructuradas: Implicaciones Competitivas para los Destinos Turísticos. Revista Asturiana de Economía - RAE, 35, 2006. P. 69-91.

SANTANA TALAVERA, A. Antropología y Turismo: ¿Nuevas hordas viejas culturas?. Barcelona: Ariel, 1997.

SANTANA TALAVERA, A. Imaginando la imagen en turismo: un viaje de ida y vuelta. La Imagen de Andalucía en el Discurso Turístico. Seminario. Centro de Estudios Andaluces, Consejería de la Presidencia, Centro Andaluz de Arte Contemporáneo, Isla de la Cartuja, Sevilla. 26 de septiembre de 
2007. Disponível em: www.centrodeestudiosandaluces.es/datos/paginas/programa_andalucia_ turismo.pdf. Acesso em: 14 abr. 2011.

SANTANA TALAVERA, A. Antropologia do Turismo: analogias, encontros e relações. São Paulo: Aleph, 2009.

SANTANA TALAVERA, A. \& PINTO, R. Tourism in the Consumer Society: Anthropologic Subsidies to the Static Subsystem Figuration. Journal of Hospitality and Tourism, v. 6, 2008. P. 87110.

SANTANA TALAVERA, A., DIAZ RODRIGUEZ, P. e RODRIGUEZ DARIAS, A. Las nuevas formas de turismo: causas y características. Revista Brasileira de Pesquisa em Turismo. v.4, n.3, 2010. P.54-70.

SELWYN, T. (Ed.). The tourist image: myths and myth making in tourism. Chichester: John Wiley \& Sons, 1996.

SHILS, E. Centro e Periferia. Lisboa: Difel, 1992.

SILVANO, F. À Procura de olhares Cúmplices: A Produção Social da Paisagem na Vila de Vizela. In: SEIXAS, P., PEREIRO PÉREZ, X. e SANTOS, P. Cultura e Arquitectura: Incursións Antropolóxicas no Espacio Construído. Santiago de Compostela: Edicións Lea, 1998. P. 135-147.

SIMONICCA, A. Antropologia del turismo: Strategie di ricerca e contesti etnografici. Roma: Carocci, 2001.

SIMONICCA, A. Conflicto(s) e Interpretación: Problemas de la Antropología del Turismo en las Sociedades Complexas. In: LAGUNAS, D. (Coord.). Antropología y Turismo. Claves Culturales y Disciplinares. México, D. C.: Plaza y Valdés, 2007. P. 27-46.

SMITH, V. \& W. EADINGTON (Eds.). Tourism alternatives. Chichester: John Wiley \& sons, 1994.

TAPACHAI, N. \& WARYSZAK, R. An Examination of the Role of Beneficial Image in Tourist Destination Selection. Journal of Travel Research, 39(1), 2000. P. 37-44.

TOMIKAWA, J. A Importância da imagem no processo de escolha da destinação turística. Monografia de especialização. Curso de Especialização em Gestão e Marketing do Turismo V. Centro de Excelência em Turismo. Universidade de Brasília, 2004.

TRAVERSO CORTÉS, J. La Imagen de los Destinos Turísticos. Elemento básico en su desarrollo estratégico. I Congreso Internacional Patrimonio, Desarrollo Rural y Turismo en el Siglo XXI, Osuna, 2004.

TRIBE, J. The Indiscipline of Tourism. Annals of Tourism Research, vol. 24, n. 3, 1997. P. 638-657.

URRY, J. O Olhar do Turista: Lazer e Viagens nas Sociedades Contemporâneas. 2a . Ed. Studio Nobel/SESC: São Paulo, 1999.

\section{Recebido em: 21/08/2011}

Aprovado em: $27 / 10 / 2011$ (1 ${ }^{\text {a }}$ versão $)$ 19/03/2012 ( $2^{\text {a }}$ versão $)$ 